\title{
POLYCYSTIC OVARY SYNDROME METABOLIC AND HORMONAL DYSFUNCTION IN RELATION TO OSTEOARTHRITIS ONSET AND DEVELOPMENT: INNOCENT BYSTANDER OR MAJOR RISK FACTOR?
}

\author{
Ts. Georgiev', P. Kabakchieva ${ }^{2}$ \\ ${ }^{1}$ Clinic of Rheumatology, University Hospital “Sv. Marina”, First Department of Internal Medicine, Medical Faculty, \\ Medical University - Varna \\ ${ }^{2}$ Clinic of Endocrinology, University Hospital "Alexandrovska”, Department of Internal Medicine, Medical Faculty, \\ Medical University - Sofia \\ Clinic of Internal Diseases, Naval Hospital, Military Medical Academy - Varna
}

\begin{abstract}
The close link between osteoarthritis (OA) and metabolic disorders on the one hand and hormonal disorders on the other suggests a possible association between $O A$ and endocrine-metabolic disorders, such as PCOS. The aim of this review is to analyze the relationship between PCOS and OA, to consider the common pathogenetic mechanisms between the two conditions, and to summarize the data accumulated so far in the literature. For the purposes of our narrative review, a comprehensive search was conducted within credible databases. Our literature search found that epidemiological studies have shown a higher incidence of knee and hip OA in women with PCOS. This can be partly explained by obesity, which is a common intersection between the two conditions. Potential mechanisms among OA, PCOS, and obesity were considered. Another common point between $O A$ and $P C O S$ is that both conditions can be considered as highly heterogeneous syndromes with various etiologies, the result of a combination of systemic (genetic, hormonal, and metabolic) and local factors. To date, hyperandrogenism and greater cartilage thickness in young women with PCOS remain unclear in terms of determining the risk of developing OA. Prospective longitudinal studies are needed to assess the "fate" of the weight-bearing joints in women with PCOS, who are more likely to suffer from knee joint complaints.
\end{abstract}

Key words: osteoarthritis, knee osteoarthritis, polycystic ovary syndrome, obesity

\section{INTRODUCTION}

Polycystic ovary syndrome (PCOS) is one of the most common endocrine disorders, characterized by menstrual disturbances, clinical and biochemical hyperandrogenism, and polycystic ovarian morphology [1]. In recent years, knowledge about the syndrome has been enriched and PCOS is now perceived as an endocrine-metabolic disorder with heterogeneous clinical presentation in women of all ages. In clinical and therapeutic terms, the focus has been drawn on both the gynecological and reproductive disorders associated with the syndrome at a young age and the associated metabolic problems observed in both young and postmenopausal ages.

There is a strong link between obesity and PCOS. Compared to healthy women, women with PCOS are more likely to be obese and insulin resistant [2] increasing their risk of prediabetes, type 2 diabetes, hypertension, dyslipidemia, obstructive sleep apnea, and metabolic syndrome. These conditions are associated with chronic low-grade inflammation [3, 4], which in turn increases patients' cardiovascular risk [5]. The group of diseases characterized by chronic inflammation of low intensity includes also osteoarthritis $(\mathrm{OA})$, a highly heterogeneous disease, characterized by progressive cartilage loss and remod- eling of joint structures [6]. Recently, the concept of $\mathrm{OA}$ as a mechanical process of "wear and tear" has been refuted. The disease affects the entire joint and is accompanied by an inflammatory component [7], hormonal and metabolic imbalance. It is characterized by disorders both at the level of joint tissues and cells and in the functional unity of the body [8, 9]. Therefore, a multimodal and multilevel therapeutic approach targeting different elements of the joint would be most effective [10], especially when started in the earliest preclinical and pre-radiographic stages of the disease.

The close relationship between $\mathrm{OA}$ and metabolic disorders on the one hand and hormonal disorders on the other suggests a possible link between $\mathrm{OA}$ and endocrine-metabolic disorders, such as PCOS. Moreover, both diseases are associated with low-grade inflammation and overweight or obesity. In addition, evidence has emerged in recent years that some rheumatic diseases, including $O A$, are more common in women with PCOS than in women without PCOS with the same body mass index [11]. Therefore, hormonal and metabolic imbalance in PCOS may further increase the risk of developing OA.

The aim of this review is to analyze the relationship between PCOS and OA, to consider the com- 
mon pathogenetic mechanisms between the two conditions and to summarize the data accumulated so far in the literature.

\section{SEARCH STRATEgY}

For the purposes of our study, we used a search strategy with a systematic approach according to recent recommendations for writing a biomedical narrative review [12]. According to them, our selection of literature began with a search in the referenced databases Scopus and Medline (PubMed) without a time frame with the following keywords "osteoarthritis" or "cartilage“ and „PCOS“ or „polycystic ovary“. The initial search was performed on 30th May 2021. This review also included data from articles examining overweight and obesity in the context of $O A$ and PCOS, as well as biomarkers in PCOS associated with cartilage turnover. Finally, the references of all articles were examined in detail and relevant fulltext articles and abstracts from leading conferences were included.

\section{OBESITY IN THE CONTEXT OF POLYCYSTIC OVARY SYNDROME AND OSTEOARTHRITIS}

Obesity is a multifactorial disease affecting about $1 / 4$ of the adult population in Europe [13]. Visceral adipose tissue is a depot for various fat-soluble steroids, where intensive metabolism of sex hormones, including androgens, takes place. In recent decades, obesity research has made great strides with the discovery that adipose tissue, especially white adipose tissue (WAT), acts as an endocrine organ and modulates the metabolism of other organs through various signaling molecules [14]. In addition to hormones, adipocytes secrete various cytokines called adipokines [15] involved in impaired action and secretion of insulin and consequently lead to insulin resistance, endothelial dysfunction, atherosclerosis [16], and also maintain chronic low-grade inflammation. The association between PCOS and low-grade inflammation has been confirmed in an increasing number of studies finding elevated levels of various inflammatory markers, such as C-reactive protein (CRP) [17, 18], interleukin-6 [19], interleukin-18 [2022]. , monocyte chemoattractant protein-1 (MCP-1) [23-25], as well as the presence of endothelial dysfunction [26, 27] and increased oxidative stress [28].

There is a strong link between obesity and PCOS. The cause is still not completely clear, but data show that obesity is found in at least $30 \%$ of women with PCOS, and according to some researchers, this percentage can reach $75 \%$ [29]. The type of adipose tis- sue redistribution is essential for the observed metabolic disturbances in PCOS. The central (android) type of obesity in women with the syndrome is more often associated with hormonal disorders, menstrual disorders and infertility [30], compared to the peripheral (gynoid) type of fat distribution. Women with PCOS are mostly found to have the android type of fat distribution observed not only among obese PCOS, but also among those who are overweight or normal weight [31]. Compared to women with peripheral obesity, lower levels of sex-hormone binding globulin (SHBG), higher levels of testosterone and dihydrotestosterone [32], regardless of body mass index (BMI), were found among android-type PCOS patients [33]. BMI is an unreliable indicator of differentiation between muscle mass and body fat [34]. The waist-to-hip ratio (WHR) is one of the most commonly used anthropometric parameters for assessing central obesity and, unlike BMI, has recently been reported to correlate well with mortality [35]. A study by Gateva and Kamenov showed that waistto-height ratio (WHtR) and waist circumference were appropriate indicators in assessing cardiovascular risk and insulin resistance among patients with PCOS [36].

Likewise, there is an intimate link between $O A$ and obesity. The majority of patients with OA of the weight-bearing joints such as the knee and hip are overweight or obese [37]. Obesity is associated with an increased risk of developing radiographic tibiofemoral and patellofemoral OA [38], and high-quality evidence suggests that weight reduction is an effective modality in the treatment of OA. However, although included in most recommendations for the treatment of OA and addressed as a modifiable risk factor [39], weight loss does not occur frequently in practice. For every kilogram of body weight lost, the knee experiences a fourfold reduction in load during daily physical activity [40]. Regardless of obesity, whether hyperandrogenism, low-grade inflammation, and metabolic changes may further increase the risk of OA (Figure 1) remains a question that warrants further research.

\section{HORMONE-DEPENDENT OSTEOARTHRITIS AND THE RELATIONSHIP WITH HORMONAL CHANGES IN POLYCYSTIC OVARY SYNDROME - A FOCUS ON HYPERANDROGENISM}

A large number of observational and interventional studies have shown that cartilage loss in women depends on hormonal status [41-45]. This claim 


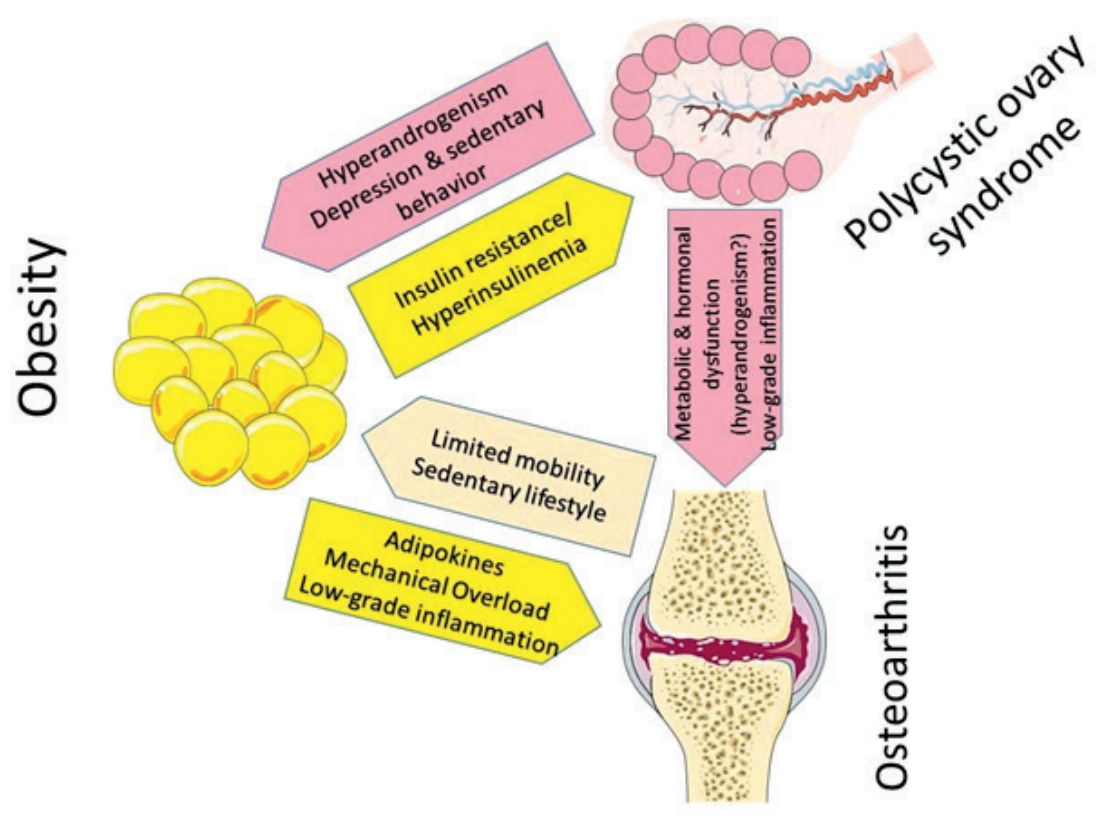

Fig. 1. Potential mechanisms of the relationship among obesity, polycystic ovary syndrome, and osteoarthritis

is supported by the fact that in $64 \%$ of women with OA involving the knee joint, symptoms begin in the first 5 years after menopause [46]. A correlation has been reported between low estrogen levels and radiographic knee joint space narrowing (an indirect sign of cartilage loss) in postmenopausal women [47]. This gives grounds for some authors to introduce the term "hormone-dependent" OA [48]. And while estrogens play a protective role in articular cartilage preservation, the effect of androgens in women is still poorly understood in terms of OA onset and development. Is it possible that high levels of androgens play a protective role similar to that observed in men [49], or rather does hyperandrogenism negatively affect articular cartilage? In this line of thought, the logical question is whether PCOS is an independent risk factor for cartilage loss in the preosteoarthritis stage and increase the risk of cartilage damage at a later age?

Hyperandrogenism is one of the most characteristic hormonal disturbances among women with PCOS and a leading diagnostic criterion according to established algorithms for diagnosis [50-52]. The mechanisms that determine it are diverse, and there is no single theory for their occurrence. It is believed that under the influence of various stimuli (insulin, insulin-like growth factor-1, luteinizing hormone, etc.) the ovary contributes the most to androgen overproduction, followed by the adrenal gland and to a lesser extent - the adipose tissue. Detection of elevated morning testosterone levels or calculated high lev- els of free testosterone or free androgen index (FAI) confirms the presence of biochemical hyperandrogenism. Of equal diagnostic weight is the presence of only clinical data on it, such as the establishment of increased hair in androgen-dependent areas (hirsutism), acne or androgenic alopecia.

The effect of androgens on joint homeostasis remains unclear in women. The results of our recent publication show that women with PCOS are more likely to suffer from knee-related symptoms, which are likely to impair their daily activities compared to their age-matched and BMI-healthy volunteers. In addition, patients with biochemical and clinical evidence of hyperandrogenism have greater thickness of femoral cartilage. FAI levels are positively correlated with cartilage thickness in women with PCOS, a relationship that lost significance after BMI correction [53].

Women with PCOS are more likely to suffer from knee and hip OA, according to a population-based study [56]. Is it possible to study sensitive biomarkers characteristic of the preclinical and pre-radiographic stages as an early diagnostic indicator of osteoarthritis? Instantaneous cartilage loss, measured by innovative serum biomarkers such as matrix metalloproteinases and cartilage oligomeric matrix protein (COMP), will undoubtedly shed light on this process.

It appears that lower serum COMP levels may be inherent in patients with PCOS and higher testosterone levels [53]. Therefore, testosterone may hypothetically play a protective role on cartilage loss 
in this group of women. In support of this claim is the fact that women with higher levels of androstenedione have a $30 \%$ lower chance of hip arthroplasty [57].

\section{COMMON BIOCHEMICAL MARKERS IN OSTEOARTHRITIS AND POLYCYSTIC OVARY SYNDROME}

Matrix metalloproteinase (MMP) 9 belongs to the large family of matrix metalloproteinases: zinc-dependent endopeptidases with extracellular proteolytic activity, involved in the degradation and remodeling of the extracellular matrix. Under physiological conditions, MMP-9 is involved in embryogenesis, neoangiogenesis, and wound healing, but its levels are increased in PCOS [58] and in a number of musculoskeletal diseases [59,60], including OA [61].

Women with normal ovulation have significantly lower levels of MMP-9, as well as different levels of tissue metalloproteinase inhibitor (TIMP)-1 and TIMP-2: molecules that inhibit the synthesis of matrix metalloproteinases [62]. In women with PCOS, increased serum MMP-9 levels may be a cause of impaired folliculogenesis [58, 63], and their reduction may lead to normalization of ovulation [64]. This is one of the putative mechanisms by which metformin favorably affects ovogenesis in PCOS [65]. The disturbed balance between MMP-9 and TIMP is probably due to the androgenic excess characteristic of these women.

Type II collagen, the most abundant collagen expressed in articular cartilage, is initially broken down by the endopeptidases MMP-1, -8, -13 and -14. Already denatured and partially degraded collagen II is further degraded by gelatinases, incl. MMP-9, and stromelysins [66]. Theoretically, high serum levels of matrix metalloproteinase- 9 in women with PCOS can lead to increased cartilage loss, as MMP-9 expression is enhanced in cartilage loss [61].

COMP is a tissue-specific matrix protein belonging to the thrombospondin family, which is synthesized by chondrocytes. It is found in large amounts in hyaline cartilage, but can also be found in serum and synovial fluid. Its concentration is ten times higher in synovial fluid than in serum [67]. However, its role in the pathogenesis of OA remains implicit. COMP serum levels are positively correlated with magnetic resonance imaging of the knee joint [68]. They can help differentiate arthritic patients from healthy controls and reflect disease activity [69-71]. On the other hand, COMP can be used for disease prognosis [72]. However, patients with PCOS do not have significantly elevated serum COMP levels, reports our study. In the group of women with the syndrome, lower levels of the biomarker are associated with higher testosterone levels [53], which again raises the question of the protective role of hyperandrogenism in the pathogenesis of OA in PCOS.

\section{IMPLICATIONS IN CLINICAL PRACTICE AND FUTURE RESEARCH}

Data from the Global Burden of Disease Study show that OA was at the forefront of the world as a cause of disability in terms of years lived with disability (YLD) [73]. Compared to 2005, the relative share of YLD has increased due to demographic aging trends in developed countries. Prevention, education and early diagnosis in specific risk groups for the development of OA may improve the quality of life, including in women with PCOS. Therefore, in addition to reproductive changes, concomitant conditions and symptoms, including musculoskeletal complaints, should be considered in those patients.

\section{CONCLUSION}

Retrospective studies suggest that OA may be a late manifestation of PCOS and thus, we should pay greater attention to musculoskeletal complaints of women with PCOS. At the time of writing this review, the significance of hyperandrogenism and increased cartilage thickness in young PCOS patients remains unclear in terms of the risk of developing OA. Prospective longitudinal studies are further warranted to assess the "fate" of the weight-bearing joints of women with PCOS, who are more likely to suffer from joint complaints and OA.

\section{Библиография / References}

1. Azziz R, Carmina E, Chen Z, et al. Polycystic ovary syndrome. Nat Rev Dis Primers. 2016 Aug 11;2:16057. doi: 10.1038/nrdp.2016.57.

2. Poretsky L, Cataldo NA, Rosenwaks Z, Giudice LC. The insulin-related ovarian regulatory system in health and disease. Endocr Rev. 1999 Aug;20(4):535-82. doi: 10.1210/ edrv.20.4.0374.

3. Hameed I, Masoodi SR, Mir SA et al. Type 2 diabetes mellitus: From a metabolic disorder to an inflammatory condition. World J Diabetes. 2015 May 15;6(4):598-612. doi: 10.4239/wjd.v6.i4.598.

4. Pedrinelli R, Dell'Omo G, Di Bello V et al G. Low-grade inflammation and microalbuminuria in hypertension. Arterioscler Thromb Vasc Biol. 2004 Dec;24(12):2414-9. doi: 10.1161/01.ATV.0000147415.40692.7f

5. Gateva A, Kamenov Z. Cardiovascular Risk Factors in Bulgarian Patients with Polycystic Ovary Syndrome and/ 
or Obesity. Obstet Gynecol Int. 2012;2012:306347. doi: 10.1155/2012/306347.

6. Loeser RF, Goldring SR, Scanzello CR, Goldring MB. Osteoarthritis: a disease of the joint as an organ. Arthritis Rheum. 2012 Jun;64(6):1697-707. doi: 10.1002/art.34453.

7. Berenbaum F. Osteoarthritis as an inflammatory disease (osteoarthritis is not osteoarthrosis!). Osteoarthritis Cartilage. 2013 Jan;21(1):16-21. doi: 10.1016/j.joca.2012.11.012.

8. Jang S, Lee K, Ju JH. Recent Updates of Diagnosis, Pathophysiology, and Treatment on Osteoarthritis of the Knee. Int J Mol Sci. 2021 Mar 5;22(5):2619. doi: 10.3390/ijms22052619.

9. Bay-Jensen AC, Hoegh-Madsen S, Dam E et al. Which elements are involved in reversible and irreversible cartilage degradation in osteoarthritis? Rheumatol Int. 2010 Feb;30(4):435-42. doi: 10.1007/s00296-009-1183-1.

10. Georgiev T. Multimodal approach to intraarticular drug delivery in knee osteoarthritis. Rheumatol Int. 2020 Nov;40(11):1763-1769. doi: 10.1007/s00296-020-04681-7.

11. Sharmeen $S$, Nomani $H$, Taub E et al. Polycystic ovary syndrome: epidemiologic assessment of prevalence of systemic rheumatic and autoimmune diseases. Clin Rheumatol. 2021 Jul 3. doi: 10.1007/s10067-021-05850-0.

12. Gasparyan AY, Ayvazyan L, Blackmore H, Kitas GD. Writing a narrative biomedical review: considerations for authors, peer reviewers, and editors. Rheumatol Int. 2011 Nov;31(11):1409-17. doi: 10.1007/s00296-011-1999-3.

13. Blundell JE, Baker JL, Boyland E et al. Variations in the Prevalence of Obesity Among European Countries, and a Consideration of Possible Causes. Obes Facts. 2017;10(1):2537. doi: $10.1159 / 000455952$.

14. Kershaw EE, Flier JS. Adipose tissue as an endocrine organ. J Clin Endocrinol Metab. 2004 Jun;89(6):2548-56. doi: 10.1210/jc.2004-0395.

15. Poirier P, Giles TD, Bray et al. American Heart Association; Obesity Committee of the Council on Nutrition, Physical Activity, and Metabolism. Obesity and cardiovascular disease: pathophysiology, evaluation, and effect of weight loss: an update of the 1997 American Heart Association Scientific Statement on Obesity and Heart Disease from the Obesity Committee of the Council on Nutrition, Physical Activity, and Metabolism. Circulation. 2006 Feb 14;113(6):898-918. doi: 10.1161/CIRCULATIONAHA.106.171016.

16. Fantuzzi G, Mazzone T. Adipose tissue and atherosclerosis: exploring the connection. Arterioscler Thromb Vasc Biol. 2007 May;27(5):996-1003. doi: 10.1161/ATVBAHA.106.131755.

17. Kelly CC, Lyall H, Petrie JR et al. Low grade chronic inflammation in women with polycystic ovarian syndrome. J Clin Endocrinol Metab. 2001 Jun;86(6):2453-5. doi: 10.1210/ jcem.86.6.7580.

18. Escobar-Morreale HF, Luque-Ramírez M, González F. Circulating inflammatory markers in polycystic ovary syndrome: a systematic review and metaanalysis. Fertil Steril. $2011 \mathrm{Mar}$ 1;95(3):1048-58.e1-2. doi: 10.1016/j.fertnstert.2010.11.036.

19. Alissa EM, Algarni SA, Khaffii AJ, Al Mansouri NM. Impact of interlukin- 6 on central obesity measures in women with polycystic ovarian syndrome. J Obstet Gynaecol. 2020 Nov;40(8):1133-1137.doi:10.1080/01443615.2019.1697219.

20. Escobar-Morreale HF, Botella-Carretero JI, Villuendas $\mathrm{G}$ et al. Serum interleukin-18 concentrations are increased in the polycystic ovary syndrome: relationship to insulin resistance and to obesity. J Clin Endocrinol Metab. 2004 Feb;89(2):80611. doi: $10.1210 /$ jc.2003-031365.
21. Zhang YF, Yang YS, Hong $\mathrm{J}$ et al. Elevated serum levels of interleukin-18 are associated with insulin resistance in women with polycystic ovary syndrome. Endocrine. 2006 Jun;29(3):419-23. doi: 10.1385/ENDO:29:3:419.

22. Dawood A, Alkafrawy N, Saleh $S$ et al. The relationship between IL-18 and atherosclerotic cardiovascular risk in Egyptian lean women with polycystic ovary syndrome. Gynecol Endocrinol. 2018 Apr;34(4):294-297. doi: 10.1080/09513590.2017.1395835.

23. González F, Rote NS, Minium J, Kirwan JP. Evidence of proatherogenic inflammation in polycystic ovary syndrome. Metabolism. 2009 Jul;58(7):954-62. doi: 10.1016/j.metabol.2009.02.022.

24. Glintborg D, Andersen M, Richelsen B, Bruun JM. Plasma monocyte chemoattractant protein-1 (MCP-1) and macrophage inflammatory protein-1alpha are increased in patients with polycystic ovary syndrome (PCOS) and associated with adiposity, but unaffected by pioglitazone treatment. Clin Endocrinol (Oxf). 2009 Nov;71(5):652-8. doi: 10.1111/j.13652265.2009.03523.x

25. Hu W, Qiao J, Yang Y et al. Elevated C-reactive protein and monocyte chemoattractant protein-1 in patients with polycystic ovary syndrome. Eur J Obstet Gynecol Reprod Biol. 2011 Jul;157(1):53-6. doi: 10.1016/j.ejogrb.2011.03.015.

26. Paradisi G, Steinberg HO, Hempfling A et al. Polycystic ovary syndrome is associated with endothelial dysfunction. Circulation. 2001 Mar 13;103(10):1410-5. doi: 10.1161/01. cir.103.10.1410

27. Carmina E, Orio F, Palomba $S$ et al. Endothelial dysfunction in PCOS: role of obesity and adipose hormones. Am J Med. 2006 Apr;119(4):356.e1-6. doi: 10.1016/j.amjmed.2005.10.059.

28. Sabuncu T, Vural H, Harma M, Harma M. Oxidative stress in polycystic ovary syndrome and its contribution to the risk of cardiovascular disease. Clin Biochem. 2001 Jul;34(5):40713. doi: 10.1016/s0009-9120(01)00245-4.

29. Diamanti-Kandarakis E, Dunaif A. Insulin resistance and the polycystic ovary syndrome revisited: an update on mechanisms and implications. Endocr Rev. 2012 Dec;33(6):9811030. doi: 10.1210/er.2011-1034.

30. Gambineri A, Laudisio D, Marocco $C$ et al. Obesity Programs of nutrition, Education, Research and Assessment (OPERA) group. Female infertility: which role for obesity? Int J Obes Suppl. 2019 Apr;9(1):65-72. doi: 10.1038/ s41367-019-0009-1.

31. Pasquali R, Gambineri A, Pagotto U. The impact of obesity on reproduction in women with polycystic ovary syndrome. BJOG. 2006 Oct;113(10):1148-59. doi: 10.1111/j.14710528.2006.00990.x

32. Kirschner MA, Samojlik E, Drejka M et al. Androgen-estrogen metabolism in women with upper body versus lower body obesity. J Clin Endocrinol Metab. 1990 Feb;70(2):4739. doi: 10.1210/jcem-70-2-473.

33. Gambineri A, Pelusi C, Vicennati $V$ et al. Obesity and the polycystic ovary syndrome. Int J Obes Relat Metab Disord. 2002 Jul;26(7):883-96. doi: 10.1038/sj.ijo.0801994.

34. Romero-Corral A, Somers VK, Sierra-Johnson J et al. Diagnostic performance of body mass index to detect obesity in patients with coronary artery disease. Eur Heart J. 2007 Sep;28(17):2087-93. doi: 10.1093/eurheartj/ehm243.

35. Coutinho T, Goel K, Corrêa de Sá D et al. Central obesity and survival in subjects with coronary artery disease: a systematic review of the literature and collaborative analy- 
sis with individual subject data. J Am Coll Cardiol. 2011 May 10;57(19):1877-86. doi: 10.1016/j.jacc.2010.11.058.

36. Gateva AT, Kamenov ZA. Markers of visceral obesity and cardiovascular risk in patients with polycystic ovarian syndrome. Eur J Obstet Gynecol Reprod Biol. 2012 Oct;164(2):161-6. doi: 10.1016/j.ejogrb.2012.05.037.

37. Georgiev T. Clinical characteristics and disability in patients with knee osteoarthritis: real world experience from Bulgaria. Reumatologia. 2019;57(2):78-84. doi: 10.5114/ reum.2019.84812

38. Hart HF, van Middelkoop M, Stefanik JJ et al. Obesity is related to incidence of patellofemoral osteoarthritis: the Cohort Hip and Cohort Knee (CHECK) study. Rheumatol Int. 2020 Feb;40(2):227-232. doi: 10.1007/s00296-019-04472-9.

39. Georgiev T, Angelov AK. Modifiable risk factors in knee osteoarthritis: treatment implications. Rheumatol Int. 2019 Jul;39(7):1145-1157. Doi: 10.1007/s00296-019-04290-z.

40. Kuster MS, Wood GA, Stachowiak GW, Gächter A. Joint load considerations in total knee replacement. J Bone Joint Surg Br. 1997 Jan;79(1):109-13. doi: 10.1302/0301-620x.79b1.6978.

41. Sowers MR, McConnell D, Jannausch M et al. Estradiol and its metabolites and their association with knee osteoarthritis. Arthritis Rheum. 2006 Aug;54(8):2481-7. doi: 10.1002/ art.22005.

42. Valdes AM, Van Oene M, Hart DJ et al. Reproducible genetic associations between candidate genes and clinical knee osteoarthritis in men and women. Arthritis Rheum. 2006 Feb;54(2):533-9. doi: 10.1002/art.21621. Erratum in: Arthritis Rheum. 2009 Jan;60(1):178.

43. Jin SY, Hong SJ, Yang $\mathrm{HI}$ et al. Estrogen receptor-alpha gene haplotype is associated with primary knee osteoarthritis in Korean population. Arthritis Res Ther. 2004;6(5):R41521. doi: $10.1186 /$ ar1207.

44. Cooper C, Egger P, Coggon D et al. Generalized osteoarthritis in women: pattern of joint involvement and approaches to definition for epidemiological studies. J Rheumatol. 1996 Nov;23(11):1938-42.

45. Szoeke CEI, Cicuttini FM, Guthrie JR et al. Factors affecting the prevalence of osteoarthritis in healthy middle-aged women: data from the longitudinal Melbourne Women's Midlife Health Project. Bone. 2006 Nov;39(5):1149-1155. doi: 10.1016/j.bone.2006.05.016.

46. Nadkar MY, Samant RS, Vaidya SS, Borges NE. Relationship between osteoarthritis of knee and menopause. J Assoc Physicians India. 1999 Dec;47(12):1161-3.

47. Bergink AP, van Meurs JB, Loughlin J et al. Estrogen receptor alpha gene haplotype is associated with radiographic osteoarthritis of the knee in elderly men and women. Arthritis Rheum. 2003 Jul;48(7):1913-22. doi: 10.1002/art.11046.

48. Herrero-Beaumont G, Roman-Blas JA, Castañeda S, Jimenez SA. Primary osteoarthritis no longer primary: three subsets with distinct etiological, clinical, and therapeutic characteristics. Semin Arthritis Rheum. 2009 Oct;39(2):7180. doi: 10.1016/j.semarthrit.2009.03.006.

49. Hanna F, Ebeling PR, Wang $Y$ et al. Factors influencing longitudinal change in knee cartilage volume measured from magnetic resonance imaging in healthy men. Ann Rheum Dis. 2005 Jul;64(7):1038-42. doi: 10.1136/ard.2004.029355.

50. Rotterdam ESHRE/ASRM-Sponsored PCOS Consensus Workshop Group. Revised 2003 consensus on diagnostic criteria and long-term health risks related to polycystic ovary syndrome. Fertil Steril. 2004 Jan;81(1):19-25. doi: 10.1016/j. fertnstert 2003.10.004.
51. Zawadzki JK. Dunaif A. Diagnostic criteria for polycystic ovary syndrome: towards a rational approach. Polycystic Ovary Syndrome 1995;377-84.

52. Goodman NF, Cobin RH, Futterweit W et al. American Association of Clinical Endocrinologists (AACE); American College of Endocrinology (ACE); Androgen Excess and PCOS Society (AES). AMERICAN ASSOCIATION OF CLINICAL ENDOCRINOLOGISTS, AMERICAN COLLEGE OF ENDOCRINOLOGY, AND ANDROGEN EXCESS AND PCOS SOCIETY DISEASE STATE CLINICAL REVIEW: GUIDE TO THE BEST PRACTICES IN THE EVALUATION AND TREATMENT OF POLYCYSTIC OVARY SYNDROME-PART 1. Endocr Pract. 2015 Nov;21(11):1291-300. doi: 10.4158/EP15748.DSC.

53. Kabakchieva P, Georgiev T, Gateva A et al. Polycystic ovary syndrome and (pre)osteoarthritis: assessing the link between hyperandrogenism in young women and cartilage oligomeric matrix protein as a marker of cartilage breakdown. Clin Rheumatol. 2021 May 4. Doi: 10.1007/s10067-021-05753-0.

54. Velasquez MT, Katz JD. Osteoarthritis: another component of metabolic syndrome? Metab Syndr Relat Disord. 2010 Aug;8(4):295-305. doi: 10.1089/met.2009.0110.

55. Ramly B, Afiqah-Aleng N, Mohamed-Hussein ZA. Protein-Protein Interaction Network Analysis Reveals Several Diseases Highly Associated with Polycystic Ovarian Syndrome. Int J Mol Sci. 2019 Jun 18;20(12):2959. doi: 10.3390/ ijms20122959.

56. Sanchez-Santos, MT, Rubin KH, Glintborg D et al. Prevalence and incidence of clinically diagnosed knee, hip and hand osteoarthritis in women with polycystic ovary syndrome: a National Register-Based Study. Osteoarthritis and Cartilage, 2018;26, S200. doi: 10.1016/j.joca.2018.02.425.

57. Hussain SM, Cicuttini FM, Bell RJ et al. Incidence of total knee and hip replacement for osteoarthritis in relation to circulating sex steroid hormone concentrations in women. Arthritis Rheumatol. 2014 Aug;66(8):2144-51. doi: 10.1002/ art.38651.

58. Lewandowski KC, Komorowski J, O'Callaghan $\mathrm{CJ}$ et al Increased circulating levels of matrix metalloproteinase-2 and -9 in women with the polycystic ovary syndrome. J Clin Endocrinol Metab. 2006 Mar;91(3):1173-7. doi: 10.1210/ jc. 2005-0648.

59. Giannelli G, Erriquez R, lannone F et al. MMP-2, MMP-9, TIMP-1 and TIMP-2 levels in patients with rheumatoid arthritis and psoriatic arthritis. Clin Exp Rheumatol. 2004 MayJun;22(3):335-8.

60. Gruber BL, Sorbi D, French DL et al. Markedly elevated serum MMP-9 (gelatinase B) levels in rheumatoid arthritis: a potentially useful laboratory marker. Clin Immunol Immunopathol. 1996 Feb;78(2):161-71. doi: 10.1006/clin.1996.0025.

61. Zeng GQ, Chen AB, Li W et al. High MMP-1, MMP-2, and MMP-9 protein levels in osteoarthritis. Genet Mol Res. 2015 Nov 23;14(4):14811-22. doi: 10.4238/2015.November.18.46.

62. Baka S, Zourla K, Kouskouni E et al. Matrix metalloproteinases 2 and 9 and their tissue inhibitors in the follicular fluid of patients with polycystic ovaries undergoing in vitro fertilisation. In Vivo. 2010 May-Jun;24(3):293-6.

63. Goldman S, Shalev E. MMPS and TIMPS in ovarian physiology and pathophysiology. Front Biosci. 2004 Sep 1;9:247483. doi: $10.2741 / 1409$.

64. Lahav-Baratz S, Kraiem Z, Shiloh H et al. Decreased expression of tissue inhibitor of matrix metalloproteinases in follicular fluid from women with polycystic ovaries compared with 
normally ovulating patients undergoing in vitro fertilization. Fertil Steril. 2003 Mar;79(3):567-71. doi: 10.1016/s00150282(02)04838-0.

65. Chen Z, Wei H, Zhao X et al. Metformin treatment alleviates polycystic ovary syndrome by decreasing the expression of MMP-2 and MMP-9 via H19/miR-29b-3p and AKT/ mTOR/autophagy signaling pathways. J Cell Physiol. 2019 Nov;234(11):19964-19976. doi: 10.1002/jcp.28594.

66. Galasso O, Familiari F, De Gori M, Gasparini G. Recent findings on the role of gelatinases (matrix metalloproteinase-2 and -9 ) in osteoarthritis. Adv Orthop. 2012;2012:834208. doi: 10.1155/2012/834208.

67. Smith RK, Heinegård D. Cartilage oligomeric matrix protein (COMP) levels in digital sheath synovial fluid and serum with tendon injury. Equine Vet J. 2000 Jan;32(1):52-8. doi: 10.2746/042516400777612053.

68. Bruyere O, Collette J, Kothari M et al. Osteoarthritis, magnetic resonance imaging, and biochemical markers: a one year prospective study. Ann Rheum Dis. 2006 Aug;65(8):1050-4. doi: 10.1136/ard.2005.045914.

69. Vilím V, Olejárová M, Machácek S et al. Serum levels of cartilage oligomeric matrix protein (COMP) correlate with

Постъпил за печат: 19.07.2021 2.

$\triangle$ Адрес за кореспонденция:

Д-р Цветослав Георгиев

ORCID iDs: 0000-0002-1652-4648

e-mail: tsetso@medfaculty.org

tel.: +359896666133

Д-р Пламена Кабакчиева - ORCID iDs: 0000-0003-3577-0577 radiographic progression of knee osteoarthritis. Osteoarthritis Cartilage. 2002 Sep;10(9):707-13. doi: 10.1053/ joca.2002.0819.

70. Singh S, Shahi U, Kumar D, Shahi NT. Serum Cartilage Oligomeric Matrix Protein: Tool for early diagnosis and grading of severity of primary knee osteoarthritis. Int J Osteol Orthop 2014;1: 1-7.

71. Awadallah AM, Gehan HS, Tarek MK. Serum level of cartilage oligomeric matrix protein as a screening modality for osteoarthritis among knee joint pain patients. J Am Sci, 2010;6(12).

72. Clark AG, Jordan JM, Vilim $V$ et al. Serum cartilage oligomeric matrix protein reflects osteoarthritis presence and severity: the Johnston County Osteoarthritis Project. Arthritis Rheum. 1999 Nov;42(11):2356-64. doi: $\quad 10.1002 / 1529-0131(199911) 42: 11<2356:: A I D-A N-$ $\mathrm{R} 14>3.0 . \mathrm{CO} ; 2-\mathrm{R}$

73. Vos T, Abajobir AA, Abbafati $C$ et al. Global, regional, and national incidence, prevalence, and years lived with disability for 328 diseases and injuries for 195 countries, 1990-2016: a systematic analysis for the global burden of disease study 2016. Lancet. 2017; 390:1211-1259.

Submitted: 19.07.2021

$\triangle$ Correspondence address:

Tsvetoslav Georgiev, MD

ORCID iDs: 0000-0002-1652-4648

e-mail: tsetso@medfaculty.org

tel.: +359896666133

Plamena Kabakchieva, MD - ORCID iDs: 0000-0003-3577-0577 